\title{
Accidental exposures to peanut in a large cohort of Canadian children with peanut allergy
}

\author{
Sabrine Cherkaoui ${ }^{1}$, Moshe Ben-Shoshan², Reza Alizadehfar ${ }^{3}$, Yuka Asai $^{4}$, Edmond Chan ${ }^{5}$, Stephen Cheuk ${ }^{6}$, \\ Greg Shand ${ }^{7}$, Yvan St-Pierre ${ }^{8}$, Laurie Harada ${ }^{9}$, Mary Allen ${ }^{10}$ and Ann Clarke ${ }^{11^{*}}$
}

\begin{abstract}
Background: We previously estimated that the annual rate of accidental exposure to peanut in 1411 children with peanut allergy, followed for 2227 patient-years, was 11.9\% (95\% Cl, 10.6, 13.5). This cohort has increased to 1941 children, contributing 4589 patient-years, and we determined the annual incidence of accidental exposure, described the severity, management, location, and identified associated factors.

Findings: Children with physician-confirmed peanut allergy were recruited from Canadian allergy clinics and allergy advocacy organizations from 2004 to May 2014. Parents completed questionnaires regarding accidental exposure to peanut over the preceding year. Five hundred and sixty-seven accidental exposures occurred in 429 children over 4589 patient-years, yielding an annual incidence rate of $12.4 \%(95 \% \mathrm{Cl}, 11.4,13.4)$. Of 377 accidental exposures that were moderate or severe, only 109 (28.9\%) sought medical attention and of these 109, only 40 (36.7\%) received epinephrine. Of the 181 moderate/severe accidental exposures treated outside a health care facility, only $11.6 \%$ received epinephrine. Thirty-seven percent of accidental exposures occurred at home. In multivariate analyses, longer disease duration, recruitment through an allergy advocacy association, and having other food allergies decreased the likelihood of accidental exposures. Age $\geq 13$ years at study entry and living with a single parent increased the risk.
\end{abstract}

Conclusion: Despite increased awareness, accidental exposures continue to occur, mainly at home, and most are managed inappropriately by both health care professionals and caregivers. Consequently, more education is required on the importance of strict allergen avoidance and the need for prompt and correct management of anaphylaxis.

Keywords: Peanut allergy, Accidental exposure, Epidemiology, Food allergy, Treatment

\section{Introduction}

Research conducted over the past 25 years has estimated that the annual rate of accidental exposure (AE) in children with peanut and/or nut allergy ranges between 3 and $50 \%[1-6]$. We previously conducted the largest longitudinal study on the rate and predictors of $\mathrm{AE}$ in children with peanut allergy and observed that in a Canadian cohort of 1411 children with peanut allergy, recruited between 2004 and 2009, and followed for 2227 patient-years, the annual rate of $\mathrm{AE}$ was $11.9 \%$ (95\% confidence interval, CI, 10.6, 13.5) [7]. The cohort has increased to 1941 children, providing 4589 patient-years of follow-up, and in

\footnotetext{
* Correspondence: aeclarke@ucalgary.ca

${ }^{11}$ Division of Rheumatology, Department of Medicine, University of Calgary, Calgary, AB, Canada

Full list of author information is available at the end of the article
}

this manuscript, we determined the annual incidence of $\mathrm{AE}$ in this expanded cohort and described the severity, management, and location of the AEs, and identified factors associated with $\mathrm{AE}$.

\section{Methods}

\section{Study design}

Children with physician-confirmed peanut allergy (eligibility criteria below) were recruited from the Allergy Clinics at the Montreal Children's Hospital $(\mathrm{MCH})$ and British Columbia's Children's Hospital (BCCH) and Canadian food allergy advocacy organizations; recruitment began at the $\mathrm{MCH}$ in 2004, at $\mathrm{BCCH}$ in 2013, and from the associations in 2006 and continued from all sources through to May 2014. Details on the cohort have been published elsewhere [7-10]. Patients were mailed a 
questionnaire at study entry (Additional file 1) and every two years (Additional file 2); starting in 2010, follow-up questionnaires were administered annually (Additional file 2). Details collected on AEs included the food ingested and the signs, symptoms, location, and treatment. Parents also reported on demographics, the allergic child's history of atopy, and the child's initial reaction to peanut.

The study was approved by the McGill University Health Centre and BCCH Research Ethics Board.

\section{Criteria for diagnosis of peanut allergy}

Children were considered allergic to peanut if they had:

- A convincing history $[6,11]$ of an allergic reaction and a positive skin prick test $(\mathrm{SPT}) \geq 3 \mathrm{~mm}$ to peanut or peanut-specific IgE $\geq 0.35 \mathrm{kU} / 1$ [12-14] or

- An uncertain history of an allergic reaction or no previous exposure and either a positive $\mathrm{SPT} \geq 3 \mathrm{~mm}$ AND peanut-specific IgE $\geq 15 \mathrm{kU} / \mathrm{L}[15,16]$ OR a positive challenge to peanut.

A convincing clinical history of peanut allergy was defined as a minimum of two mild signs or symptoms or either one moderate or one severe sign or symptom that was likely IgE mediated and occurred within $120 \mathrm{~min}$ after peanut ingestion or contact. Reactions were considered mild if they involved only pruritus, urticaria, flushing, or rhinoconjunctivitis; moderate if angioedema, throat tightness, gastrointestinal complaints, or breathing difficulties (other than wheeze); and severe if wheeze, cyanosis, or circulatory collapse $[6,11]$.

\section{Statistical analysis}

Descriptive statistics were compiled for all variables. The annual incidence rate of $\mathrm{AE}$ was expressed as the number of events divided by the sum of the patient-years at risk. As a sensitivity analysis, the rate of $\mathrm{AE}$ was also calculated by: 1) excluding those with one mild symptom or no previous exposure and positive confirmatory tests and 2) including only those with a positive food challenge, history of anaphylaxis [17], or convincing history with a SPT $\geq$ $8 \mathrm{~mm}$ or a peanut-specific IgE $\geq 15 \mathrm{kU} / \mathrm{L}$ [15].

Univariate and multivariate Cox regression analyses were used to examine potential predictors of the hazard of an AE. Predictors were selected using backward stepwise selection. Potential predictors for the Cox regression included sex, ethnicity, age at study entry, disease duration, source of recruitment (i.e., food allergy advocacy associations versus allergy clinics), other atopic conditions, severity of initial reaction to peanut, whether the child attended a school prohibiting peanut, and parental factors (i.e., living arrangement, age, level of education and employment). All statistical analyses were done with Stata, version 13 (StataCorp LP, Texas).

\section{Findings}

\section{Patient characteristics}

Of 2759 patients surveyed, 1941 (70.4\%) responded with $35.9 \%$ of respondents recruited from the allergy advocacy associations. Patients were predominantly male (62.1\%) and Caucasian (88.0\%). The mean age (standard deviation, $\mathrm{SD})$ and disease duration at the time of the initial questionnaire was 6.9 (4.0) and 4.7 (4.0) years, respectively, and the mean length of follow up was 2.4 years (SD 1.4) (Table 1).

Participants experiencing an AE were younger and had a shorter disease duration at the time of the initial questionnaire, had a longer observation interval, were less likely to have other food allergies and to have an initial reaction that was moderate or severe, and had slightly younger parents (Table 1).

Overall, 69 (3.6\%) participants were defined as having peanut allergy based on a positive oral food challenge, 1698 (87.5\%) had a convincing clinical history and positive confirmatory testing, and 64 (3.3\%) had one mild symptom and positive confirmatory testing and 110 (5.7\%) had no clinical reaction and positive confirmatory testing.

\section{Risk, severity, management, and location of accidental exposures}

Five hundred and sixty-seven AEs occurred in 429 children over 4589 patient-years, yielding an annual incidence rate of $12.4 \%$ (95\% CI, 11.4, 13.4). Figure 1 depicts these AEs stratified by disease duration. The rate was similar when those with one mild symptom or no previous exposure and positive confirmatory tests were excluded ( $\mathrm{n}$ remaining $=1767$; rate of $\mathrm{AE}$ : $13.3 \%, 95 \% \mathrm{CI}, 12.2$, 14.4) and when only those with a positive food challenge, history of anaphylaxis, or a convincing history and a $\mathrm{SPT} \geq 8 \mathrm{~mm}$ or a peanut-specific $\mathrm{IgE} \geq 15 \mathrm{kU} / \mathrm{L}$ were included ( $n=1541$; rate of AE: $13.5 \%$ CI $12.4,14.8)$.

Among 567 AEs, 149 (26.3\%) of the corresponding initial reactions to peanut were mild, 284 (50.1\%) were moderate, and $64(11.3 \%)$ severe; for 70 (12.3\%) AEs, there was no previous peanut exposure (and these patients were diagnosed based on confirmatory testing) or the reaction severity was unknown. Among 463 AEs preceded by an initial reaction (with known severity), $26.3 \%$ of AEs were more severe than the initial reaction, $21.0 \%$ were less severe, and $52.7 \%$ were of comparable severity.

No treatment was administered for $36.5 \%$ of the 148 mild AEs, $25.6 \%$ of the 292 moderate AEs, and $14.1 \%$ of the 85 severe AEs (the reaction severity was unknown for $42 \mathrm{AE}, 4$ of these received no treatment, and for 37 of these the treatment was unknown). Of 292 AEs that were moderate, only $73(25.0 \%)$ sought medical attention and of these 73, only 22 (30.1\%) received epinephrine. Of the 144 moderate AEs treated outside a health care facility, only 13 (9.0\%) received epinephrine (the remaining 75 
Table 1 Comparing demographic and clinical characteristics of participants with and without accidental exposures

\begin{tabular}{|c|c|c|c|}
\hline & $\begin{array}{l}\text { With AE } \\
n=429\end{array}$ & $\begin{array}{l}\text { Without AE } \\
\mathrm{n}=1512\end{array}$ & $\begin{array}{l}\text { Difference } \\
(95 \% \mathrm{Cl})\end{array}$ \\
\hline Male, \% & 62.0 & 62.2 & $-0.2(-5.4,5.0)$ \\
\hline Ethnicity, \% Caucasian & 86.5 & 88.5 & $-2.0(-5.6,1.6)$ \\
\hline Age at diagnosis, ${ }^{*}$ years, mean (SD) & $2.3(2.1)$ & $2.1(1.7)$ & $0.2(0,0.4)$ \\
\hline Age at initial questionnaire, years, mean (SD) & $6.2(3.9)$ & $7.1(4.0)$ & $-0.9(-1.3,-0.4)$ \\
\hline Disease duration at initial questionnaire, years, mean (SD) & $3.9(3.7)$ & $5.0(4.0)$ & $-1.1(-1.5,-0.7)$ \\
\hline Observation interval, years, mean (SD) & $2.6(1.4)$ & $2.3(1.4)$ & $0.3(0.2,0.4)$ \\
\hline Age $\geq 13$ years at initial questionnaire, $\%$ & 8.9 & 9.9 & $-1.0(-4.1,2.1)$ \\
\hline Recruited through allergy associations, \% & 32.2 & 37.0 & $-4.8(-9.8,0.2)$ \\
\hline Personal history of eczema, \% & 51.3 & 51.7 & $-0.4(-5.7,5.0)$ \\
\hline Personal history of asthma, \% & 45.7 & 49.9 & $-4.2(-9.5,1.2)$ \\
\hline Personal history of rhinitis, \% & 33.6 & 35.6 & $-2.0(-7.1,3.1)$ \\
\hline Personal history of other food allergy, \% & 45.9 & 51.9 & $-6.0(-11.3,-0.7)$ \\
\hline Initial reaction moderate/severe, ${ }^{* *} \%$ & 58.9 & 69.1 & $-10.2(-15.4,-5.0)$ \\
\hline Initial reaction severe, $\%$ & 11.2 & 14.5 & $-3.3(-6.8,0.2)$ \\
\hline Attending a school prohibiting peanut, \% & 80.3 & 80.2 & $0.1(-4.4,4.6)$ \\
\hline Single parent household, \% & 8.4 & 6.6 & $1.8(-1.2,4.8)$ \\
\hline Age of parents, years, mean (SD) & $38.6(5.8)$ & $39.2(5.7)$ & $-0.7(-1.3,-0.1)$ \\
\hline \multicolumn{4}{|l|}{ Mother's education and work status, \% } \\
\hline Post-secondary education & 87.4 & 88.7 & $-1.3(-4.8,2.3)$ \\
\hline Completed university & 60.7 & 61.0 & $-0.3(-5.5,5.0)$ \\
\hline Currently employed & 68.7 & 70.1 & $-1.5(-6.6,3.7)$ \\
\hline \multicolumn{4}{|l|}{ Father's education and work status, \% } \\
\hline Post-secondary education & 78.0 & 79.5 & $-1.5(-6.0,3.0)$ \\
\hline Completed university & 51.6 & 53.8 & $-2.2(-7.6,3.3)$ \\
\hline Currently employed & 88.8 & 91.6 & $-2.8(-6.2,0.7)$ \\
\hline
\end{tabular}

*The age of diagnosis of peanut allergy was the earliest of the age of the first reaction or confirmatory testing.

**Mild signs/symptoms: pruritus, urticaria, flushing, rhinoconjunctivitis; moderate: angioedema, throat tightness, gastrointestinal complaints, breathing difficulties other than wheeze; severe: wheeze, cyanosis, circulatory collapse $[6,11]$.

moderate AEs received no treatment). Of the 85 AEs that were severe, only $36(42.4 \%)$ sought medical attention and of these 36,18 (50.0\%) received epinephrine. Of the 37 severe AEs treated outside a health care facility, only 8 (21.6\%) received epinephrine (the remaining 12 severe AEs received no treatment).

Thirty-seven percent of AEs occurred at home, 14.3\% at relatives'/friends' homes, $9.3 \%$ in restaurants, $4.9 \%$ at schools/day-cares prohibiting peanut, $3.0 \%$ at schools/ day-cares allowing peanuts, and $31.6 \%$ at other or unknown places.

\section{Predictors of accidental exposure}

Longer disease duration (adjusted hazard ratio (HR): 0.90, 95\% CI: 0.88, 0.93), recruitment from food allergy advocacy associations (HR: 0.75, 95\% CI: 0.63, 0.91), and having other food allergies (HR: $0.81,95 \% \mathrm{CI}: 0.68,0.96)$ decreased the likelihood of an $\mathrm{AE}$ (Table 2). Age $\geq$
13 years at study entry (HR: 2.22, 95\% CI: 1.44, 3.41) and residing in a single parent household (HR: 1.55, 95\% CI: 1.14, 2.10) increased the risk of AE.

\section{Discussion}

We have conducted the largest longitudinal study on the rate, treatment, and predictors of $\mathrm{AE}$ in children with peanut allergy. In our cohort of 1941 children, 567 AEs occurred in 429 children over 4589 patient-years, yielding an annual incidence rate of $12.4 \%$ (95\% CI, 11.4, 13.4). Of 377 AEs that were moderate or severe, only $109(28.9 \%)$ sought medical attention and of these, only 40 (36.7\%) received epinephrine. In multivariate analyses, longer disease duration, recruitment through an allergy advocacy association, and having other food allergies decreased the likelihood of AEs, whereas age $\geq$ 13 years at study entry and living with a single parent increased the risk. 


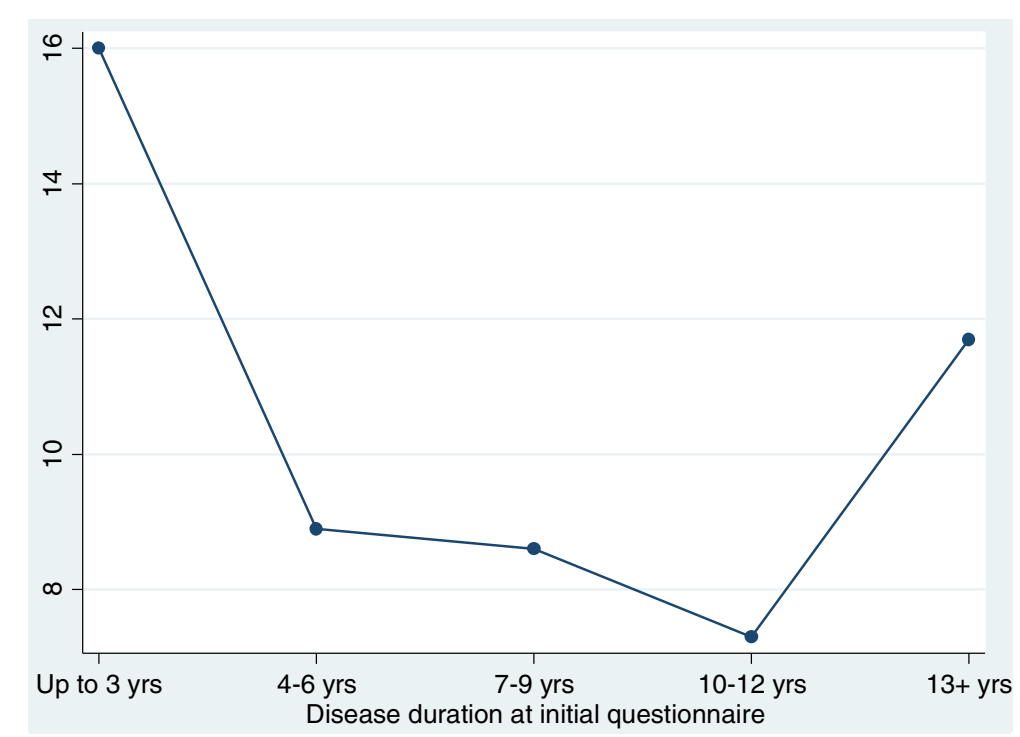

Figure 1 Annual incidence rate of accidental exposure stratified by disease duration.

Longer disease duration is likely associated with a lower risk of AE because participants develop better allergen avoidance strategies over time. Participants who were adolescents at study entry are at higher risk, given equal disease duration, presumably due to their risktaking behaviours [18]. Combining the independent effect of disease duration and age therefore explains the U-shaped relationship between disease duration and incidence of AE depicted in Figure 1. Participants with other food allergies likely perceive themselves at higher risk of having a severe $\mathrm{AE}$ and exercise more caution. Children recruited through food allergy advocacy associations were also less likely to experience an $\mathrm{AE}$, possibly reflecting their enhanced awareness. As it is possible that parents of children recruited from hospital allergy clinics were also members of allergy associations (but we did not inquire about this), our estimate of the lower risk associated with membership is likely conservative.

Our annual incidence rate of $12.4 \%$ is substantially lower than the $50 \%$ and $33 \%$ reported in studies conducted in 1989 [5] and 2000 [4], respectively. This likely reflects enhanced societal awareness regarding the diagnosis, risks,

Table 2 Univariate and multivariate predictors* of accidental exposures**

\begin{tabular}{|c|c|c|}
\hline & Univariate & Most informative multivariate \\
\hline & HR $(95 \% \mathrm{Cl})$ & $\mathrm{HR}(95 \% \mathrm{Cl})$ \\
\hline Caucasian & $0.70(0.54,0.90)$ & Not Included \\
\hline Age at study entry & $0.93(0.91,0.96)$ & Not Included \\
\hline Disease duration at entry & $0.92(0.89,0.94)$ & $0.90(0.88,0.93)$ \\
\hline Age $\geq 13$ years at study entry & Non Significant & $2.22(1.44,3.41)$ \\
\hline Recruited through allergy associations & $0.65(0.54,0.77)$ & $0.75(0.63,0.91)$ \\
\hline Personal history of rhinitis & $0.82(0.69,0.97)$ & Not Included \\
\hline Personal history of other food allergy & $0.75(0.64,0.89)$ & $0.81(0.68,0.96)$ \\
\hline Single parent household & $1.46(1.08,1.98)$ & $1.55(1.14,2.10)$ \\
\hline Age of parents & $0.97(0.95,0.98)$ & Not Included \\
\hline \multicolumn{3}{|l|}{ Father's education and work status } \\
\hline Currently employed & $0.72(0.55,0.94)$ & Not Included \\
\hline
\end{tabular}

HR: Hazard ratio.

*Only significant predictors are indicated.

**Potential predictors for the Cox regression included sex, ethnicity, age at study entry (i.e., at the time the patient starts to be observed, which could be up to one year prior to the initial questionnaire), disease duration, source of recruitment (i.e., food allergy advocacy associations versus allergy clinics), other atopic conditions, severity of initial reaction to peanut, whether the child attended a school prohibiting peanut, and parental factors (i.e., living arrangement, age, level of education and employment). 
and management of peanut allergy. However, our estimate exceeds that reported in recent studies. Clark et al. reported a rate of only $3.1 \%$ in 2008 , but these participants with peanut and/or nut allergy received a comprehensive management program $[1,2]$. Neuman-Sunshine et al. observed a rate of $7.3 \%$ in a cohort of 782 patients where AEs were possibly underestimated as they were ascertained by chart review and a substantial portion may not have been allergic (37.9\% were diagnosed based solely on an elevated peanut-specific IgE without any reaction) [3]. A high rate of AE has also been observed for other food allergies; Boyano-Martinez et al. reported that $40 \%$ of 88 children with allergy to cow's milk and $21 \%$ of 92 children with allergy to hen's egg reported an $\mathrm{AE}$ in the preceding year $[19,20]$.

The low rate of usage of epinephrine is consistent with other studies [21-24], which report administration of epinephrine in less then $50 \%$ of cases where it is indicated.

We did not observe a difference in the percentage of AEs occurring in schools/daycares prohibiting (4.9\%, 95\% CI, 3.3, 7.1) versus allowing peanuts $(3.0 \%, 95 \% \mathrm{CI}, 1.8$, 4.8). Failure to observe such a decreased rate in facilities restricting peanut may be due to increased awareness and enhanced vigilance among parents, school personnel, and children in schools permitting peanut. Further, peanutfree policies may create a false sense of security and foods brought to such facilities may inadvertently contain peanut and children who are allergic may believe that it is safe to share foods as they believe they are guaranteed to be peanut free.

Our study is limited in that inclusion of children with one mild symptom or no previous exposure and a peanutspecific $\operatorname{IgE} \geq 15 \mathrm{kU} / \mathrm{L}$ but having an SPT between 3 and $7 \mathrm{~mm}$ may not have been sufficiently rigorous. However, the annual rate of AE did not differ between those children with one mild symptom or no previous exposure with a peanut-specific $\operatorname{IgE} \geq 15 \mathrm{kU} / \mathrm{L}$ and SPT between 3 and $7(n=46$, rate of AE: 3.3\%, 95\% CI, 0.9, 8.5) and SPT $\geq$ $8 \mathrm{~mm}(\mathrm{n}=128$, rate of AE: $3.8 \%, 95 \% \mathrm{CI}, 2.0,6.7)$. For those 226 children with a convincing history with an SPT between 3 and $7 \mathrm{~mm}$, the point estimate of the annual rate of AE was actually $10.8 \%$ (95\% CI, 7.9, 14.5). It is possible the lower rate of $\mathrm{AE}$ observed in the 174 without a convincing history (9.0\% of the entire cohort of 1941) suggests that some of these children were only sensitized. Alternatively, they may have had a higher threshold and required a larger amount of peanut to provoke an allergic reaction. Excluding these 174 children does not result in a clinically meaningful increase in the rate of $\mathrm{AE}(\mathrm{n}=1767$, rate of AE: $13.3 \%, 95 \% \mathrm{CI}, 12.2,14.4)$ and as these children are still experiencing some AEs, omitting them from the analysis may inappropriately inflate our AE estimates.

Despite increasing efforts to provide information on the management of food allergy, AEs continue to occur, mainly in the child's home, but also in peanut free schools/day-cares. Most moderate/severe AEs are managed inappropriately by caregivers and physicians. Consequently, more education is required on the importance of strict allergen avoidance and the need for prompt and correct management of anaphylaxis.

\section{Additional files}

Additional file 1: Peanut allergy registry. Baseline questionnaire sent to patients when first joining the peanut allergy registry.

Additional file 2: Peanut allergy registry - follow up. Follow up questionnaire sent to patients participating in the peanut allergy registry.

\section{Abbreviations}

AE: Accidental exposure; BCCH: British Columbia Children's Hospital; $\mathrm{Cl}$ : Confidence interval; MCH: Montreal Children's Hospital; HR: Hazards ratio; SD: Standard deviation; SPT: Skin prick test.

\section{Competing interests}

Dr. Sabrine Cherkaoui declares that she has no competing interests.

Dr. Ben-Shoshan is a consultant for Sanofi and Novartis.

Dr. Reza Alizadehar declares that he has no competing interests.

Dr. Yuka Asai declares that she has no competing interests.

Dr. Edmond Chan reports personal fees from Sanofi and Pfizer, outside the submitted work.

Dr. Stephen Cheuk reports receiving honoraria from GSK, Merck, Pfizer, Sanofi, Novartis, Astra-Zeneca and Paladin. He is also a consultant for Sanofi, Pfizer, Novartis, Pediapharm, Gracemay.

Greg Shand declares that he has no competing interests.

Yvan St-Pierre declares that he has no competing interests.

Laurie Harada is the Executive Director of Anaphylaxis Canada. She reports Anaphylaxis Canada receiving funds from the American Peanut Council to support education efforts such as programs to train daycare workers and annual public conferences. The American Peanut Council does not have any editorial rights in the development of their resources. Anaphylaxis Canada also receives funding support from several food manufacturers, some of which produce products that do not contain peanuts. While these companies (listed on Anaphylaxis Canada's website) do not have any influence over the organization's decisions or content of resources, it is important to show source of funding. Their names are disclosed in their communications, on their website and promotional materials, e.g. if they provide sponsorship for conferences or education events.

Mary Allen declares that she has no competing interests.

Dr. Ann Clarke declares that she has no competing interests.

\section{Authors' contributions}

Conception and design: SC, MB-S, RA, YA, EC, SC, GS, YS-P, AC. Acquisition of data: MB-S, RA, YA, EC, LH, MA, AC. Analysis and interpretation of data: SC, MB-S, RA, YA, EC, SC, GS, YS-P, AC. Drafting of article: SC, AC. Revision of article critically for important intellectual content: SC, MB-S, RA, YA, EC, SC, YS-P, AC. Approval of the version to be published: SC, MB-S, RA, YA, EC, SC, GS, YS-P, LH, MA, AC. All authors read and approved the final manuscript.

\section{Funding}

This study received funding from the Foundation of the Montreal Children's Hospital, The Foundation of the McGill University Health Centre, and the Allergy Genes and Environment Network of Centres of Excellence (AllerGEN NCE).

\section{Author details}

'Division of Allergy and Clinical Immunology, Department of Medicine, University of Montreal, Montreal, QC, Canada. ${ }^{2}$ Division of Pediatric Allergy and Clinical Immunology, Department of Pediatrics, McGill University Health Centre, Montreal, QC, Canada. ${ }^{3}$ Division of Allergy and Clinical Immunology, Department of Pediatrics, McGill University Health Centre, Montreal, QC, Canada. ${ }^{4}$ Division of Dermatology, Department of Medicine, Queen's 
University, Kingston, ON, Canada. ${ }^{5}$ Division of Allergy and Immunology, Department of Pediatrics, British Columbia Children's Hospital, University of British Columbia, Vancouver, BC, Canada. ${ }^{6}$ Allergist/Clinical Immunologist, Calgary, AB, Canada. ${ }^{7}$ Division of Clinical Epidemiology, Department of Medicine, McGill University Health Centre, Montreal, QC, Canada. ${ }^{8}$ Division of Clinical Epidemiology, Department of Medicine, McGill University Health Centre, Montreal, QC, Canada. ${ }^{9}$ Anaphylaxis Canada, Toronto, ON, Canada. ${ }^{10}$ Allergy/Asthma Information Association, Toronto, ON, Canada. " ${ }^{1}$ Division of Rheumatology, Department of Medicine, University of Calgary, Calgary, AB, Canada.

Received: 14 November 2014 Accepted: 28 February 2015

Published online: 02 April 2015

\section{References}

1. Clark AT, Ewan PW. Good prognosis, clinical features, and circumstances of peanut and tree nut reactions in children treated by a specialist allergy center. J Allergy Clin Immunol. 2008;122:286-9.

2. Ewan PW, Clark AT. Efficacy of a management plan based on severity assessment in longitudinal and case-controlled studies of 747 children with nut allergy: proposal for good practice. Clin Exp Allergy. 2005;35:751-6.

3. Neuman-Sunshine DL, Eckman JA, Keet CA, Matsui EC, Peng RD, Lenehan $\mathrm{PJ}$, et al. The natural history of persistent peanut allergy. Ann Allergy Asthma Immunol. 2012;108:326,331.e3.

4. Vander Leek TK, Liu AH, Stefanski K, Blacker B, Bock SA. The natural history of peanut allergy in young children and its association with serum peanut-specific lgE. J Pediatr. 2000;137:749-55.

5. Bock SA, Atkins FM. The natural history of peanut allergy. J Allergy Clin Immunol. 1989;83:900-4.

6. Hourihane JO, Kilburn SA, Dean P, Warner JO. Clinical characteristics of peanut allergy. Clin Exp Allergy. 1997;27:634-9.

7. Nguyen-Luu NU, Ben-Shoshan M, Alizadehfar R, Joseph L, Harada L, Allen M, et al. Inadvertent exposures in children with peanut allergy. Pediatr Allergy Immunol. 2012;23:133-9.

8. Yu JW, Kagan R, Verreault N, Nicolas N, Joseph L, St Pierre Y, et al. Accidental ingestions in children with peanut allergy. J Allergy Clin Immunol. 2006;118:466-72.

9. Lavine E, Clarke A, Joseph L, Shand G, Alizadehfar R, Asai Y, et al. Peanut avoidance and peanut allergy diagnosis in siblings of peanut allergic children. Clin Exp Allergy. 2015;45:249-54.

10. Ben-Shoshan M, Kagan R, Primeau MN, Alizadehfar R, Verreault N, Yu JW, et al. Availability of the epinephrine autoinjector at school in children with peanut allergy. Ann Allergy Asthma Immunol. 2008;100:570-5.

11. Perry TT, Matsui EC, Conover-Walker MK, Wood RA. Risk of oral food challenges. J Allergy Clin Immunol. 2004;114:1164-8.

12. NIAID-Sponsored Expert Panel, Boyce JA, Assa'ad A, Burks AW, Jones SM, Sampson HA, et al. Guidelines for the diagnosis and management of food allergy in the United States: Report of the NIAID-sponsored expert panel. J Allergy Clin Immunol. 2010;126 Suppl 6:1-58.

13. Sicherer SH, Wood RA. Advances in diagnosing peanut allergy. J Allergy Clin Immunol Pract. 2013;1:1-13. quiz 14.

14. Sampson HA, Aceves S, Bock SA, James J, Jones S, Lang D, et al. Food allergy: a practice parameter update-2014. J Allergy Clin Immunol. 2014;134:1016-25. e43.

15. Roberts $G$, Lack $G$. Diagnosing peanut allergy with skin prick and specific IgE testing. J Allergy Clin Immunol. 2005;115:1291-6.

16. Sampson HA. Utility of food-specific IgE concentrations in predicting symptomatic food allergy. J Allergy Clin Immunol. 2001;107:891-6.

17. Sampson HA, Munoz-Furlong A, Campbell RL, Adkinson NF J, Bock SA, Branum A, et al. Second symposium on the definition and management of anaphylaxis: summary report-Second National Institute of Allergy and Infectious Disease/Food Allergy and Anaphylaxis Network symposium. J Allergy Clin Immunol. 2006;117:391-7.

18. Mackenzie H, Roberts $G$, van Laar D, Dean T. Teenagers' experiences of living with food hypersensitivity: a qualitative study. Pediatr Allergy Immunol. 2010;21:595-602.

19. Boyano-Martinez T, Garcia-Ara C, Pedrosa M, Diaz-Pena JM, Quirce S. Accidental allergic reactions in children allergic to cow's milk proteins. J Allergy Clin Immunol. 2009;123:883-8.
20. Boyano-Martinez T, Pedrosa M, Quirce S, Garcia-Ara C. Accidental allergic reactions in children allergic to hen's egg. J Investig Allergol Clin Immunol. 2012;22:109-15.

21. Furlong TJ, DeSimone J, Sicherer SH. Peanut and tree nut allergic reactions in restaurants and other food establishments. J Allergy Clin Immunol. 2001;108:867-70

22. Sicherer SH, Furlong TJ, DeSimone J, Sampson HA. The US peanut and tree nut allergy registry: characteristics of reactions in school and day care. J Pediatr. 2001;138:560-5.

23. Jacobs TS, Greenhawt MJ, Hauswirth D, Mitchell L, Green TD. A survey study of index food-related allergic reactions and anaphylaxis management. Pediatr Allergy Immunol. 2012;23:582-9.

24. Sclar DA, Lieberman PL. Anaphylaxis: underdiagnosed, underreported, and undertreated. Am J Med. 2014;127 Suppl 1:1-5.

\section{Submit your next manuscript to BioMed Central and take full advantage of:}

- Convenient online submission

- Thorough peer review

- No space constraints or color figure charges

- Immediate publication on acceptance

- Inclusion in PubMed, CAS, Scopus and Google Scholar

- Research which is freely available for redistribution 